\title{
CORRECTION OF ROTATIONAL MALUNION OF A PHALANX BY METACARPAL OSTEOTOMY
}

\author{
A. P. Pieron, Leyiden, The Netherlands \\ From the Anna Kliniek, Leyden
}

Rotational deformity is mentioned in the literature by many authors as a complication of fracture of a phalanx (Campbell 1963, Flynn 1966, Rank and Wakefield 1953, Stark 1970). Generally, correction of the deformity by division through the fracture site is assumed without further discussion to be the procedure of choice. This view is taken even in the latest writings (Huffstadt 1969).

\section{CASE REPORT}

A man aged thirty years-a professional violinist-had in 1968 received a direct blow on the medial aspect of the left hand, which caused an oblique fracture of the proximal phalanx of the little finger (Fig. 1). Treatment was by immobilisation in the "neutral" position with a
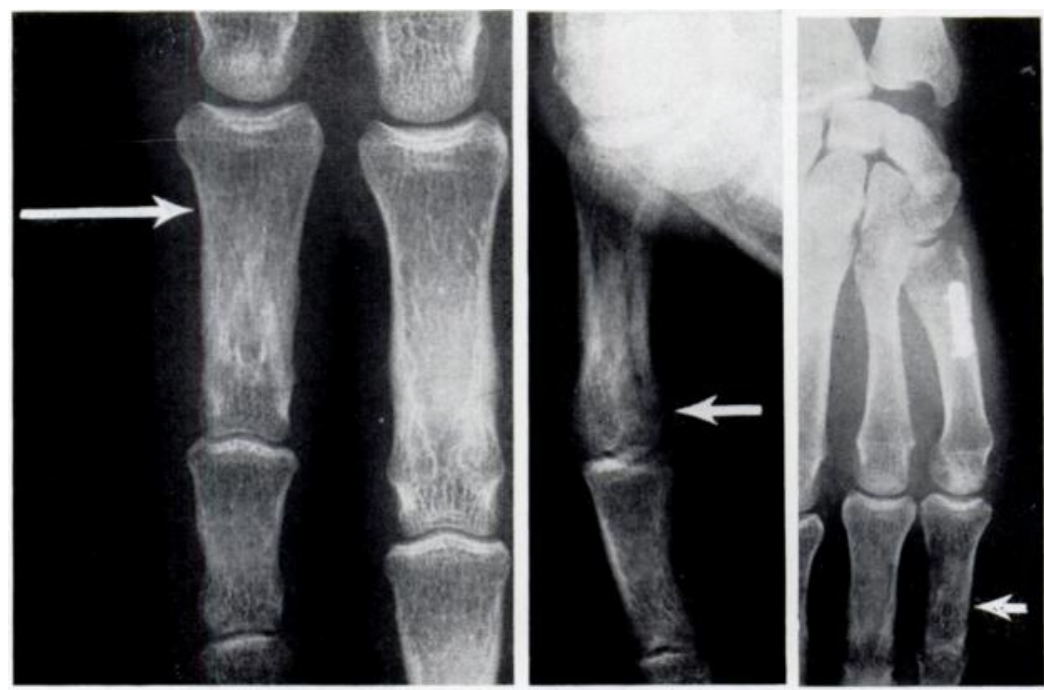

FIG. 1

Radiograph of the fractured proximal fifth phalanx of the left hand. Arrow shows the fracture site as an oblique transradiant line running to the opposite side just proximal to the proximal interphalangeal joint. In the lateral projection (right) the arrow shows the distal end of the fracture line. Radiograph at right shows appearance after operation.

plaster splint for six weeks. After removal of the splint the finger was stiff: this was a source of severe handicap. With much effort the finger was mobilised and full movement of all the joints was obtained (Figs. 2 to 4 ).

When he resumed playing the violin he noticed that his little finger could not be moved to the right place on the string. He tried to control this motion of the little finger, but without success (Fig. 3). After two years he came again for advice. There was a rotational deformity of 15 degrees. In consequence he was unable to touch the thenar eminence with the little finger. Correction of the deformity was proposed, but the patient was very nervous about ending up 


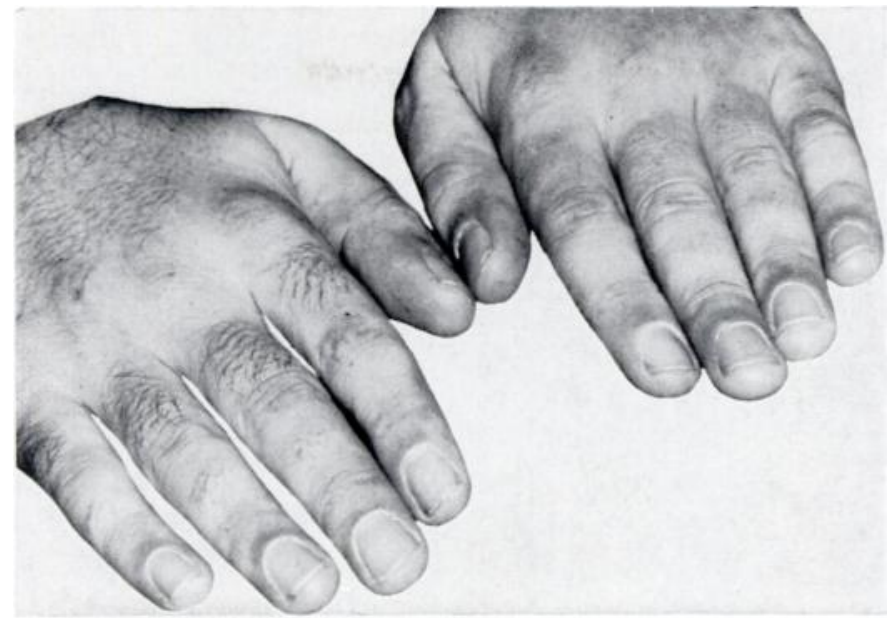

FIG. 2

Patient with fingers extended. No abnormality is seen between the right and left little fingers, except for a slight difference in the direction of the finger nail.

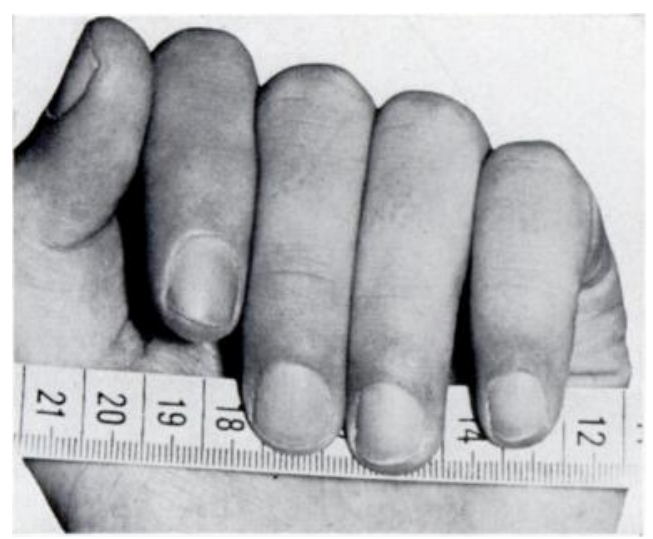

Fig. 3

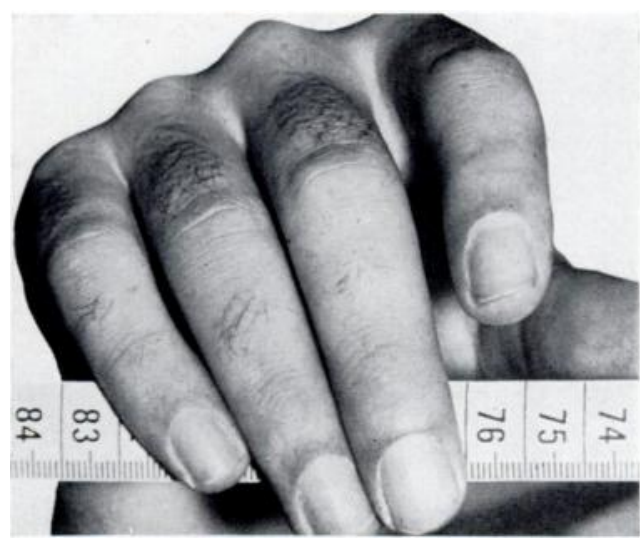

FIG. 4

Figure 3-Left hand: flexion of the fingers shows the gap between the tips of the ring and little fingers. Figure 4 Right hand: normal relation between ring and little fingers.

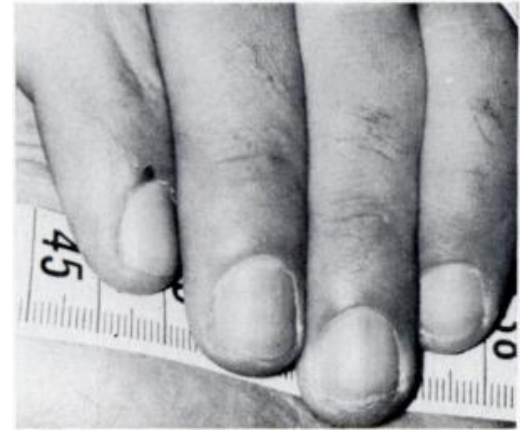

FiG. 5

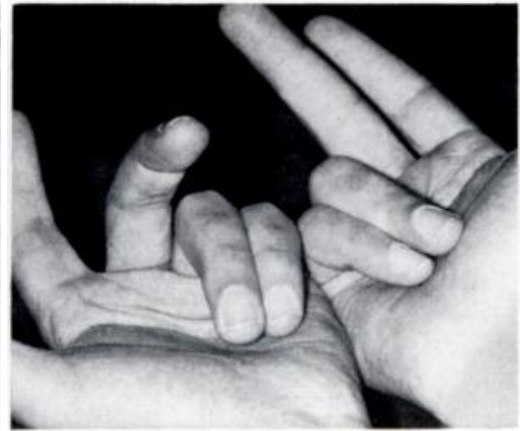

Fig. 6

After operation. The gap between the tips of the ring and little fingers in flexion has disappeared.

VOL. 54 B, NO. 3, AUGUST 1972 
with a stiff finger again. It was decided to correct the deformity by cutting through the metacarpal bone. The site of election was the proximal fourth of the fifth metacarpal. After rotation of 15 degrees, the fragments were fixed with a miniature plate and screws. After operation a loose pressure dressing with the fingers in spherical grip (Landsmeer 1962) and a volar plaster splint were applied. Active exercises began on the day after operation. The fragments were united in six weeks. At present the patient is playing his violin much more easily (Figs. 5 and 6).

\section{DISCUSSION}

In a detailed anatomical study Landsmeer analysed the articulations of the human finger (Landsmeer 1955, Landsmeer and Ansingh 1957). He stressed the asymmetrical course and the differences of insertion of the oblique "collateral ligaments" of the metacarpo-phalangeal joints.

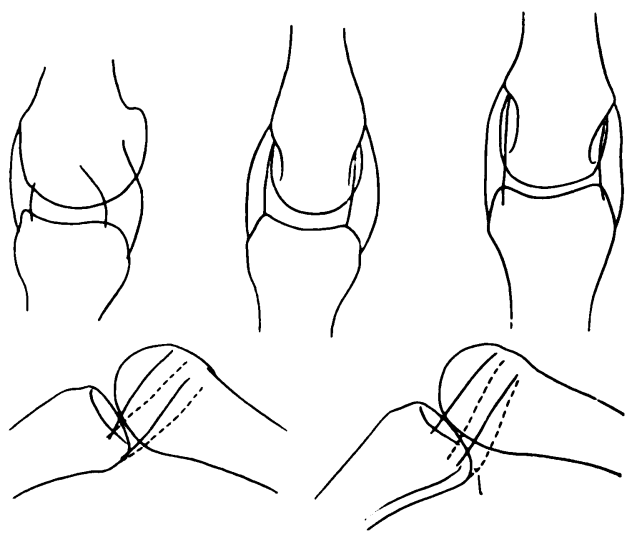

FIG. 7

Drawings of radiographs of the metacarpophalangeal joints of the fingers after insertion of wires into the ligaments. The top line shows the asymmetrical metacarpal heads and the asymmetrical arrangement of the ligaments in extension. From left to right: index, middle and ring finger. The lower line shows the asymmetrical arrangements of ligaments of the little finger in flexion. The continuous lines are the radial and the interrupted lines are the ulnar ligaments. Left: neutral position; right: lateral rotation. (After Landsmeer 1955.)

This asymmetry is most marked in the index and middle fingers and much less so in the ring and little fingers. In the latter these ligaments are equal in size. The obliquity of the "lateral" ligaments allow for motion in flexion, extension and abduction.

Unlike other workers Landsmeer did not find any slackening of these ligaments during abduction and therefore these ligaments are not true collateral ligaments. This motion only takes place with the metacarpo-phalangeal joint in extension.

When flexion takes place the oblique lateral ligaments move to a different position in relation to the metacarpo-phalangeal joints and now become true collateral ligaments. Consequently, in maximal flexion abduction is no longer possible (Fig. 7). Furthermore, the metacarpal heads too are asymmetrical. Therefore the only movement in full flexion is a few degrees of rotation. This rotation can be shown in the living hand-for instance in the middle finger-by moving the finger-tip across the palm.

Because of this anatomical arrangement the tip of the fifth digit in flexion touches the palm of the hand radially to its corresponding metacarpal. Therefore, any malrotation in union of a phalanx will cause a marked disturbance, which manifests itself fully in flexion. 
Landsmeer (1962) distinguishes between spherical and cylindrical grip. In the latter the metacarpo-phalangeal joint is brought into maximal lateral rotation. This was precisely the position that this patient could not achieve because of the union in malrotation.

Weckesser (1965) described two cases with fractures respectively of the proximal phalanx of the index and ring fingers, in which there was malunion with rotational deformity. He corrected the deformity by osteotomy at the base of the corresponding metacarpal. The result in both cases was good. The operation, of course, rotates the whole finger radialwards, so that-in theory at least—-this method is only suitable for the correction of minor deformities.

\section{SUMMARY}

1. Rotational deformity of a finger caused by malunion of a phalangeal fracture has been corrected by metacarpal osteotomy.

2. Because of the anatomical arrangement of the metacarpo-phalangeal joint this method gives good control of the distal phalanges.

3. Division through the metacarpal rather than through the phalanx avoids adhesions in the flexor and extensor mechanisms and in the joints of the fingers, allows early mobilisation and is an easier procedure.

The author wishes to express his thanks to Professor Dr F. Duyfjes, Head of the Anna Kliniek, for permission to publish this case and to Professor Dr J. M. F. Landsmeer for stimulating criticism.

\section{REFERENCES}

Campbell's Operative Orthopaedics (1963): Edited by A. H. Crenshaw. Fourth edition. Saint Louis: The C. V. Mosby Company.

FLYNN, J. E. (1966): Hand Surgery. Baltimore: Williams and Wilkins Company.

HuffSTADT, A. J. C. (1969): The Hand. Reparative and Reconstructive Surgery. Leiden: Stafleu's wetenschappelijke uitgeversmij N.V.

LANDSMeER, J. M. F. (1955): Anatomical and Functional Investigations on the Articulation of the Human Finger. Acta anatomica, suppl. 24, 25, 1.

Landsmeer, J. M. F. (1962): Power Grip and Precision Handling. Annals of Rheumatic Diseases, $21,164$.

LANDSmeer, J. M. F., and ANsingh, H. R. (1957): X-ray Observations on Rotation of the Fingers in the Metacarpo-phalangeal Joints. Acta anatomica, 30, 404.

Rank, B. K., and Wakefield, A. R. (1953): Surgery of Repair as Applied to Hand Iniuries. Edinburgh and London: E. \& S. Livingstone Ltd.

Stark, H. H. (1970): Troublesome Fractures and Dislocations of the Hand. American Academy of Orthopaedic Surgeons Instructional Course Lectures, 19, 130.

WeCKesser, E. C. (1965): Rotational Osteotomy of the Metacarpal for Overlapping Fingers. Journal of Bone and Joint Surgery, 47-A, 751.

vol. 54 B, NO. 3, AUGUST 1972 